\title{
Epidemiology of autistic disorder in Bahrain: prevalence and obstetric and familial characteristics
}

\author{
A.M. Al-Ansari ${ }^{7}$ and M.M. Ahmed ${ }^{2}$
}

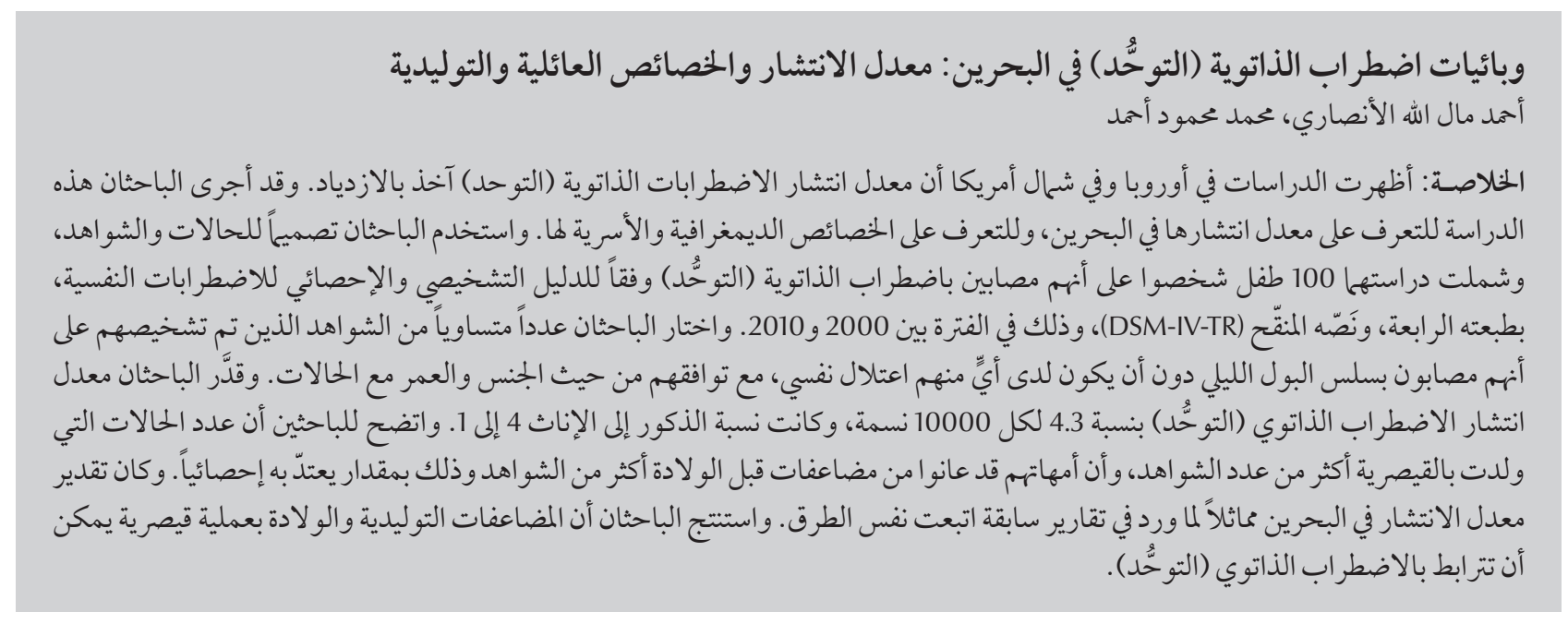

ABSTRACT European and North American studies show that the prevalence of autistic disorder is increasing. This study was performed to identify the prevalence of autistic disorder in Bahrain, and determine some of the demographic and family characteristics. Using a case-control design, 100 children who received a diagnosis of autistic disorder according to DSM-IV-TR during the period 2000-2010 were selected. An equal number of controls who had received a diagnosis of nocturnal enuresis and no psychopathology were selected, matched for sex and age group. The prevalence of autistic disorder was estimated as 4.3 per 10000 population, with a male:female sex ratio of 4:1. Significantly more cases than controls were delivered by caesarean section and had mothers who suffered prenatal complications. The prevalence estimate in Bahrain is comparable to previous reports using similar methods. Obstetric complications and caesarean section delivery may be associated with autistic disorder.

\section{Épidémiologie du trouble autistique à Bahreïn : prévalence et caractéristiques obstétricales et familiales}

RÉSUMÉ Des études européennes et nord-américaines indiquent que la prévalence du trouble autistique est en augmentation. La présente étude a été réalisée afin de connaître la prévalence du trouble autistique à Barheïn, et de déterminer certaines caractéristiques démographiques et familiales. À l'aide d'un plan d'étude cas-témoins, 100 enfants ayant reçu un diagnostic de trouble autistique selon le Manuel diagnostique et statistique des troubles mentaux (quatrième édition) au cours de la période 2000-2010 ont été sélectionnés. Des témoins en nombre équivalent ayant reçu un diagnostic d'énurésie nocturne mais qui étaient exempts de psychopathologie ont été sélectionnés, appariés pour le sexe et la tranche d'âge. La prévalence du trouble autistique a été estimée à 4,3 pour 10000 dans la population, avec un rapport de masculinité de 4 pour 1 . Le nombre de nourrissons nés par césarienne et dont la mère avait souffert de complications prénatales était nettement supérieur dans le groupe des cas par rapport aux témoins. L'estimation de la prévalence à Bahreïn était comparable aux rapports antérieurs ayant utilisé des méthodes similaires. Des complications obstétricales et une naissance par césarienne pourraient être associées à un trouble autistique.

'Department of Psychiatry, College of Medicine and Medical Sciences, Arabian Gulf University, Manama, Bahrain (Correspondence to A.M. AlAnsari:aansari@health.gov.bh).

${ }^{2}$ Department of Ear, Nose and Throat, Head and Neck, King Hamad University Hospital, Al Muharraq, Bahrain.

Received: 18/04/12; accepted: 19/06/12 


\section{Introduction}

Autistic disorder is a chronic and severe neurodevelopmental disorder characterized by impairments in social interaction, reciprocal communication, patterns of stereotyped behaviour and onset before age 3 years [1]. Although its etiology remains unknown, there is evidence to suggest that it is common among the same families and possibly influenced by environmental factors [2,3]. Prevalence estimates have increased in the last 2 decades and range from 0.7 per 10000 population to 72.6 per 10000 with a mean of 20.6 per 10000 . According to the Centers for Disease Control's Autism and Developmental Disabilities Monitoring Networkabout 1 in 88 children in the United States of America (USA) is identified with autism spectrum disorder [4]. The mean male:female ratio is 4.2:1 [5]. Factors playing a major role in this increase in prevalence include broadening of the definition of autistic disorder and improved awareness of the disorder with a concomitant development of services; other factors such as sample size, publication year and geographic location of the studies play a role in variations in estimates [6-8].

In the 1990s autistic disorder was rarely referred to or diagnosed in the Child and Adolescent Psychiatric Unit (CAPU) in Bahrain. In the last 5 years, however, autistic disorder is diagnosed on weekly basis and today CAPU uses a set of formal instruments for autistic disorder diagnosis. To the author's knowledge, the prevalence of autistic disorder was never estimated in Bahrain. Studies on the prevalence of autistic disorder in the region are scarce. In Oman Al-Farsi et al. in 2011 reported an autistic disorder estimate of 1.4 per 10000 with a male:female ratio of $4: 1$ [9].

The present study was a part of prospective case-control study investigation of the relationship between autistic disorder and advancing parental age. In this paper we report an estimate of the prevalence of autistic disorder in Bahrain, together with the sex distribution and possible associated factors such prenatal and postnatal complications, type of delivery and other personal and familial characteristics.

\section{Methods}

\section{Study setting}

Bahrain is an archipelago situated in the Gulf region, east of Saudi Arabia. It covers an area of approximately 750 $\mathrm{km}^{2}$, and has an estimated population of 1.25 million in 2010 . Health services are free and accessible to all residents. The country is characterized by a low infant mortality rate, 7.2 per 1000, and high life expectancy of 74.8 years.

Annually, nearly 30 new cases of autistic disorder are diagnosed in CAPU, the only referral unit for autistic disorder in Bahrain, and referred to 3 community centres that care for autistic disorder. In the school year 2010-11 a small group of autistic disorder children were integrated into the regular public school system. The centres can accommodate around 120 autistic disorder persons aged 2-21 years. Youths above the age of 21 years can join an afternoon social club that is open 6 days a week.

\section{Study design and sample}

The prevalence of autistic disorder was estimated by dividing the number of cases (100) by the Bahraini population for 2005 multiplied by 100000 .

The study of associated factors utilized a case-control design. The study group were all cases attending the CAPU, the Alwafa centre, Al Rashad centre and youth club, who received a diagnosis of autistic disorder over the time period 2000-10 and who met the inclusion criteria $(n=100)$. The diagnosis was reached according to the Modified Checklist for Autism in Toddlers [9], the Diagnostic and Statistical Manual of Mental Disorders (4th edition, text revision) [10] and the Childhood Autism Rating Scale [11]. The control group consisted of an equal number of children and youths attending the unit over the same time period, randomly selected from a pool of 350 individuals matched for age (in 5-year age groups), sex, social class, parent's education and family history. The controls were children and youths receiving a diagnosis of nocturnal enuresis $(n=64)$, mild behaviour disorder $(n=10)$ and no psychopathology $(n=$ 26). The study received the approval of the ethics committee of the Ministry of Health of Bahrain.

\section{Data collection}

Medical records from CAPU and social records from participating centres were reviewed by the co-author and related data were abstracted. The data were entered into a form specially designed for the study by a co-author. The items on the form aimed to collect data on child's age and sex, birth order, language development (based on parent's reports), sleeping and eating patterns, and on the mother's pregnancy and delivery, including duration of pregnancy (term or preterm), type of delivery (normal, lower segment caesarean section or assisted delivery), and any prenatal, natal and postnatal complications and stressful life events around the time of delivery (based on parents reports). The parents' section included age at birth of the child, educational level, employment, family history of autistic disorder, consanguinity (1st or 2nd degree) and any history of psychiatric or medical disorders (based on parents' reports) The social class was constructed following Hollingshead and Redlich's 5-point scale [12].

Neither the cases nor their parents were interviewed. Parents of 9 cases and 21 controls were contacted by 
telephone or home visits by the CAPU social worker to complete some missing data. All parents gave informed consent prior to inclusion in the study. Only 1 case from the study group was excluded due to doubtful diagnosis.

\section{Analysis}

The data were entered and analysed using SPSS, version 16.0. The data were presented as simple frequencies and mean and standard deviation (SD). Odds ratios (OR) were calculated and the chi-squared test of significance was used to assess differences between cases and controls wherever applicable.

\section{Results}

\section{Prevalence}

The case register method revealed a prevalence of 4.3 per 10000 population using an estimated Bahraini population for the year 2005 .

\section{Characteristics of autistic disorder cases}

Table 1 shows that males outnumbered females among cases by a ratio 4:1. The mean age was 10.5 (SD 6.4) years, range 2-27 years. One-third presented with sleep and eating disorders (39\% and 30\% respectively). Speech was totally absent in $38 \%$ of cases, $64 \%$ had some language production and $15 \%$ were able to communicate occasionally using short sentences. The great majority of mothers (83\%) did not report any stressful events during pregnancy, delivery and the early postpartum period. Nearly one-third of autistic disorder cases (29\%) had blood-related parents.

Table 2 shows that more than three-quarters of parents had received either high school or college education (77\% mothers and $82 \%$ fathers). Most fathers were employed while $68 \%$ of mothers were housewives; $10 \%$ of fathers were retired. A family

\begin{tabular}{|c|c|}
\hline Variable & $\begin{array}{c}\% \text { of cases } \\
(n=100)\end{array}$ \\
\hline \multicolumn{2}{|l|}{ Sex } \\
\hline Male & 80 \\
\hline Female & 20 \\
\hline \multicolumn{2}{|l|}{ Sleep ${ }^{a}$} \\
\hline No disturbance & 54 \\
\hline Insomnia & 38 \\
\hline Hypersomnia & 1 \\
\hline \multicolumn{2}{|l|}{ Eating behaviour $^{a}$} \\
\hline No disturbance & 68 \\
\hline Increased appetite & 6 \\
\hline Decrease appetite & 24 \\
\hline \multicolumn{2}{|l|}{ Speech } \\
\hline No speech & 38 \\
\hline Words only & 34 \\
\hline Sentences & 13 \\
\hline $\begin{array}{l}\text { Occasional use of communicative } \\
\text { language }\end{array}$ & 15 \\
\hline \multicolumn{2}{|l|}{ Stressful events } \\
\hline Absent & 83 \\
\hline Divorce & 8 \\
\hline Death & 4 \\
\hline Others & 5 \\
\hline \multicolumn{2}{|l|}{ Consanguinity } \\
\hline 1st degree & 17 \\
\hline 2nd degree & 12 \\
\hline Not related & 71 \\
\hline
\end{tabular}

${ }^{a}$ Missing data in some cases.

history of autistic disorder was present in $12 \%$ of the studied families. A small number of families (7\%) reported the presence of psychiatric disorders among parents compared with $12 \%$ with chronic physical disorders. The majority of cases $(85 \%)$ came from the lower social classes 4 and 5 .

\section{Case-control comparisons: mother's pregnancy and birth history}

Cases did not differ from controls in the mother's duration of pregnancy and rate of postnatal complications (Table 3). However autistic disorder cases had a significantly higher incidence of delivery complications (i.e. lower caesarean section or assisted delivery) (24\% versus 12\% for controls, $\mathrm{OR}=2.51,95 \% \mathrm{CI}: 1.12-5.63$ ) $(P=0.025)$. In addition $15 \%$ of mothers of autistic disorder cases had prenatal complications compared with $4 \%$ control cases $(\mathrm{OR}=4.19,95 \% \mathrm{CI}$ : $1.34-13.1)(P=0.014)$.

\section{Discussion}

Results from this case register study in Bahrain estimated a prevalence of autistic disorder of 4.3 per 10000 , which is similar to other studies using similar data collecting methods $[5,13-18]$. This rate is nearly 4 -fold the rate reported from the Gulf region [19]. In spite of the fact that the case 


\begin{tabular}{|c|c|c|}
\hline \multirow[t]{2}{*}{ Variable } & \multicolumn{2}{|c|}{$\%$ of cases $(n=100)$} \\
\hline & Mothers & Fathers \\
\hline \multicolumn{3}{|l|}{ Education $^{a}$} \\
\hline Illiterate & 4 & 0 \\
\hline Read \& write & 1 & 1 \\
\hline Primary education & 7 & 10 \\
\hline Secondary education & 36 & 42 \\
\hline College education & 41 & 40 \\
\hline \multicolumn{3}{|l|}{ Current employment } \\
\hline Housewife/unemployed & 68 & 0 \\
\hline Employed & 31 & 89 \\
\hline Student & 0 & 1 \\
\hline Retired & 1 & 10 \\
\hline \multicolumn{3}{|l|}{ Family history of autism } \\
\hline Present & 3 & 9 \\
\hline Absent & 97 & 91 \\
\hline \multicolumn{3}{|l|}{ Psychiatric illness } \\
\hline Present & 4 & 3 \\
\hline Absent & 96 & 97 \\
\hline \multicolumn{3}{|l|}{ Chronic physical illness } \\
\hline Present & 2 & 10 \\
\hline Absent & 98 & 90 \\
\hline
\end{tabular}

${ }^{a}$ Missing data in some cases. register method is usually accused of underestimation [20], the authors do not believe that this applies to our study. First, because the coverage of services by our unit involves all the islands of Bahrain, as CAPU is located in a central area and people reside within $10 \mathrm{~km}$ in either direction. Secondly, the level of awareness among professionals and the population is high as CAPU receives on a daily basis children referred with delays in language development from the network of 24 health centres attached to the main general hospital. Thirdly, all suspected cases of autistic disorder are assessed in CAPU by one team and so case definition does not present an obstacle. However, we do believe that a small number of cases within wealthy families are treated abroad, and that there may be other unidentified individuals with autistic disorder who have higher intellectual functioning and who might escape detection and enter directly to the public school system.

\begin{tabular}{|c|c|c|c|c|c|}
\hline \multirow[t]{2}{*}{ Variable } & $\begin{array}{c}\text { Cases } \\
(n=100)\end{array}$ & $\begin{array}{l}\text { Controls } \\
(n=100)\end{array}$ & OR & $95 \% \mathrm{Cl}$ & $P$-value \\
\hline & $\%$ & $\%$ & & & \\
\hline \multicolumn{6}{|l|}{ Duration of pregnancy } \\
\hline Preterm & 9 & 8 & $\mathrm{n} / \mathrm{a}$ & $\mathrm{n} / \mathrm{a}$ & $\mathrm{n} / \mathrm{a}$ \\
\hline Term & 91 & 92 & & & \\
\hline \multicolumn{6}{|l|}{ Type of delivery } \\
\hline Normal & 76 & 89 & 2.51 & $1.12-5.63$ & 0.025 \\
\hline Caesarean section or assisted birth & 24 & 11 & & & \\
\hline \multicolumn{6}{|l|}{ Prenatal complications } \\
\hline Present & 15 & 4 & 4.19 & $1.34-13.1$ & 0.014 \\
\hline Absent & 85 & 96 & & & \\
\hline \multicolumn{6}{|l|}{ Postnatal complications } \\
\hline Present & 6 & 7 & 0.84 & $0.27-2.59$ & 0.760 \\
\hline Absent & 94 & 93 & & & \\
\hline \multicolumn{6}{|l|}{ Social class } \\
\hline Class 3 & 15 & 12 & $\mathrm{n} / \mathrm{a}$ & $\mathrm{n} / \mathrm{a}$ & $\mathrm{n} / \mathrm{a}$ \\
\hline Class 4 & 14 & 21 & & & \\
\hline Class 5 & 71 & 67 & & & \\
\hline
\end{tabular}

$n / a=$ not assessed $; O R=$ odds ratio $; C I=$ confidence interval . 
The background characteristics of the cases revealed an overall male:female sex ratio of $4: 1$, in line with many other studies [7]. The proportion of cases $(62 \%)$ who had some language production is considered high. This could be explained by the fact that many cases had received several years of extensive training in communication skills and by the wide range of ages studied. The rate of sleep and eating disturbances among cases (39\% and $30 \%$ ) was lower than figures of $44 \%$ $88 \%$ and $90 \%$ reported by other studies $[21,22]$. The prevalence of stressful life events is probably similar to that in the society at large and is considered to be relatively small.

The figure for consanguinity among the parents of autistic disorder cases seems to be high (29\%). The overall rate of consanguinity in Bahrain is declining over time; at present it is around $15 \%$, which is a decrease from the higher level of $39 \%$ in 1996 [23]. The figure of $29 \%$ is probably typical for parents who got married in the 1990s and not for the present population. Consanguinity was found to be an associated factor for mild intellectual disability in a communitybased, case-control study [24]. In the present study, we did not compare this factor with the control group because we controlled for social class (which is to some extent a proxy for consanguinity) because of its relevance to both groups.

The rate of family history of autistic disorder among the relatives of cases (12\%) supports the role of genetic factors, which has been suggested by other studies [25]. The prevalence of psychiatric disorders was not compared between the relatives of cases and controls. The types of disorders could not be investigated further. The majority of parents of cases were healthy individuals.

In the case-control comparisons prenatal obstetric complications (OR $=4.19)$ as well as caesarean section/ assisted delivery $(\mathrm{OR}=2.51)$ were significantly more common among cases; this finding is in accordance with other reported studies [25]. The rate of caesarean section deliveries among cases (24\%) exceeded the acceptable rate of $15 \%$ suggested by the World Health Organization [26] and a recent report from the main referral general hospital in Saudi Arabia [27].

The study had some limitations. The nature of the study design being a retrospective analysis of events has its own known limitations. Ideally, the control group should be derived from a representative community cohort, as estimates of autistic disorder calculated by case-controlled studies will not be the same as those derived from populationbased studies. Other limitations include lack of comparable data from the region and the unavailability of some data such as age of marriage and rates of obstetric complications.

\section{Conclusions}

The present study adds to the available knowledge regarding an important public health concern in the Eastern Mediterranean Region. The prevalence of autistic disorder in Bahrain was within the range reported by other studies using similar method. Boys outnumbered girls by a ratio of 4 to 1. Risk factors associated with autistic disorder were prenatal complications and caesarean section/assisted delivery. Future research should be directed towered studying risk factors derived from a population-based sample, and evaluation of rehabilitation efforts.

\section{Funding: None}

Competing interests: None declared.

\section{References}

1. Diagnostic and statistical manual of mental disorders, 4th ed. Washington DC, American Psychiatric Association, 1994.

2. Fombonne E. Epidemiological survey of autism and other pervasive developmental disorder: an update. Journal of $A u$ tism and Developmental Disorders, 2003, 33:365-382.

3. Freitag CM. The genetics of autistic disorders and its clinical relevance: a review of the literature. Molecular Psychiatry, 2007, 12:2-22.

4. New data on autism spectrum disorders. Centers for Disease Control and Prevention [online] (http://www.cdc.gov/features/countingautism/, accessed 27 June 2013).

5. Fombonne E. Epidemiology of pervasive developmental disorders. Pediatric Research, 2009, 65:591-598.

6. Fombonne E. Epidemiology of autistic disorder and other pervasive developmental disorders. Journal of Clinical Psychiatry, 2005, 66(Suppl. 10):3-8.

7. Fombonne E. The epidemiology of autism: a review. Psychological Medicine, 1999, 29:769-786.

8. Chakrabarti S, Fombonne E. Pervasive developmental disorders in preschool children, 2010. JAMA, 2001, 285:3093-3099.
9. Al-Farsi YM et al. Brief report: prevalence of autistic spectrum disorders in the Sultanate of Oman. Journal of Autism and Developmental Disorders, 2011, 41:821-825.

10. Diagnostic and statistical manual of mental disorders, 4th ed, text revision (DSM-IV-TR). Arlington, Virginina, American Psychiatric Association, 2002.

11. Shopler E, Reichler RJ, Renner BR. The Childhood Autism Rating Scale (CARS). Los Angeles, Western Psychological Services, 1988.

12. Hollingshead AB, Redlich FC. Social class and mental illness. Wiley, New York, 1958.

13. Kielinen M, Linna SL, Moilanen I. Autism in Northern Finland. European Journal of Child and Adolescent Psychiatry, 2000, 9:162-167.

14. Magnússon P, Saemundsen E. Prevalence of autism in Iceland. Journal of Autism and Developmental Disorders, 2001, 31:153-163.

15. Scott FJ et al. Prevalence of autism spectrum conditions in children aged 5-11 years in Cambridgeshire, UK. British Journal of Psychiatry, 2009, 194:500-509. 
16. Steinhausen $\mathrm{HC}$ et al. A community survey of infantile autism Journal of the American Academy of Child Psychiatry, 1986, 25:186-189.

17. Wing L. The definition and prevalence of autism. the definition and prevalence of autism: a review. European Child and Adolescent Psychiatry, 1993, 2:61-74.

18. Wong VCN, Hui SLH. Epidemiological study of autism spectrum disorder in China. Journal of Child Neurology, 2007, 23:67-72.

19. Modified Checklist for Autism in Toddlers (M-CHAT) follow-up interview $^{T M}$ Georgia State University [online] (http://www2. gsu.edu/ psydlr/Diana_L._Robins,_Ph.D._files/M-CHATInterview.pdf, accessed 27 June 2013).

20. Bristol $\mathrm{M}$ et al. State of the science in autism: report to the $\mathrm{Na}-$ tional Institute of Health. Journal of Autism and Developmental Disorders, 1996, 26:121-154.

21. Johnson KP, Malow BA. Assessment and pharmacologic treatment of sleep disturbance in autism. Child and Adolescent Psychiatric Clinics of North America, 2008, 17:773-785.
22. Schreck KA, Williams K, Smith AF. A comparison of eating behaviors between children with autism and without autism. Journal of Autism and Developmental Disorders, 2004, 34:433-438.

23. Al-Arrayed SS. The frequency of consanguineous marriage in the State of Bahrain. Bahrain Medical Bulletin, 1995, 17:63-66.

24. Al-Ansari A. Etiology of mild mental retardation among Bahraini children: a community-based case control study. Mental Retardation, 1993, 31:140-143.

25. Glasson EJ et al. Perinatal factors and the development of autism: a population study. Archives of General Psychiatry, 2004, 61:618-627.

26. The National Sentinel Section audit report. London, Royal College of Obstetricians and Gynaecologists, 2001.

27. Bondok WM. El-Shehry SH, Fadlallah SM. Trends in cesarean section rate. Saudi Medical Journal, 2011, 31:41-45.

\section{Executive Board resolution on "Comprehensive and Coordinated Efforts for the Management of Autism Spectrum Disorders”}

The 133rd Executive Board of the World Health Organization adopted a resolution on "Comprehensive and Coordinated Efforts for the Management of Autism Spectrum Disorders" (ASDs) on May 30th 2013. The resolution was co-sponsored by more than 50 countries and supported by all.

The resolution sets out a clear set of actions to facilitate comprehensive intersectoral response to the needs of persons with ASD and other developmental disorders in all countries, with high-, middle- and low-income. The resolution urges Member States to increase the capacity of health and social care systems to provide services for individuals and families with autism spectrum disorders and other developmental disorders. It highlights the importance of implementing resolution WHA66.8 on the comprehensive mental health action plan 2013-2020, as well as resolution WHA66.9 on disability, in order to scale up care for individuals with autism spectrum disorders and other developmental disorders and as an integrated component of the scale-up of care for all mental health needs.

Source: Child and AdolescentMental Health (http://www.whoint/mental_health/women_children/child_adolescent/en/index.html). 